\title{
AVES DA MARUJADA: A UTILIZAÇÃO DE PENAS NA CONFECÇÃO DO CHAPÉU DA MARUJA ${ }^{1}$
}

\author{
Ana Mabell Seixas Alves Santos ${ }^{2}$
}

\begin{abstract}
RESUMO
Este trabalho objetiva compreender a utilização de penas de aves como matéria-prima fundamental para a confecção do chapéu da maruja em Bragança-PA, enfatizando a relação entre as artesãs que produzem os chapéus e os animais escolhidos para este fim. A preferência por uma espécie de pato, que implicou no gradual desuso de penas de outras aves - tais como guarás, garças e galinhas obedece a critérios de ordem prática e estética que tem afetado a cadeia produtiva do chapéu ao longo dos anos. A obtenção e o sacrifício das aves, bem como a escolha e retirada das penas e o posterior tratamento necessário à sua durabilidade são marcados por uma relação que revela nuances de animização e modos distintos de lidar com a religiosidade. A dualidade entre os elementos humano e o não humano resulta na materialização do saber artesanal e na vivência de um ofício algumas vezes descrito como devocional. O trabalho foi desenvolvido com base em trabalho de campo, com entrevistas a cinco artesãs, e na produção bibliográfica sobre cultura material, da qual é possível destacar Miller (2010) e Hall (2003).
\end{abstract}

Palavras-chave: Chapéu. Marujada. Artesanato. Penas. Cultura Material.

\begin{abstract}
This work aims to understand the use of bird feathers as fundamental raw material for the confection of the maruja hat in Bragança-PA, emphasizing the relationship between the artisans who produce the hats and the animals chosen para for this purpose. The preference for a species of duck, which resulted in the gradual disuse of other birds - such as guarás, herons and hens -, follows practical and aesthetic criteria that has affected the productive chain of the hat over the years. The obtaining and sacrifice of birds, as well as the choice and withdrawal of the feathers and the subsequent treatment necessary to their durability are marked by a relationship that reveals nuances of animating and different ways of dealing with religiosity. The duality between the human and non-human elements results in the materialization of the craft knowledge and in the experience of an occupation sometimes described as devotional. The work was developed based on fieldwork, with interviews to five artisans, and in the bibliographical research about material culture, from which is possible to highlight Miller (2010) and Hall (2003).
\end{abstract}

Keywords: Hat. Marujada. Craft. Feathers. Material Culture.

Recebido em: 21/04/ 2017

Aprovado em: 10/05/2017

\footnotetext{
${ }^{1}$ Trabalho apresentado durante o II TRADINTER (Seminário Tradução e Interculturalidade) na Sessão 07 Reflexões sobre a relação humano e não-humano: vivências em comunidades tradicionais com animais e ou/ mitos - realizada no dia 07/12/2-16 e coordenada pelos professores Dr. Luis Junior Costa Saraiva e Dra. Roberta Sá Leitão Barboza.

${ }^{2}$ Mestranda do Programa de Pós-Graduação em Linguagens e Saberes na Amazônia da Universidade Federal do Pará. E-mail: belseixas@yahoo.com.br.
} 


\section{PLUMAS}

Começar esta análise com um título tão singelo como "plumas" pode sugerir uma errônea leveza quanto ao objeto de estudo deste trabalho: o chapéu da maruja em BragançaPA. No entanto, o título foi escolhido por outra razão que não sua textura etérea: começo pelas plumas porque elas são percebidas à primeira vista no chapéu. São postas à superfície, ocultando a trama complexa que compõe sua estrutura. Quanto à leveza, a única analogia que cabe não diz respeito à simplicidade do tema, mas à facilidade com que voam as plumas, tal como se perderam ao vento e ao tempo algumas tendências, referências e influências que formaram o chapéu da maruja tal como é hoje.

Desta forma, a trama complexa que estrutura o chapéu condiz com a complexidade dos ritos e práticas devocionais que compõem a marujada, bem como das alterações ocorridas nesta expressão da religiosidade amazônida desde sua origem, que remonta à data de 3 de setembro de $1798^{3}$. E, em que pese a vasta produção literária e acadêmica existente sobre a devoção a São Benedito em Bragança, a indumentária das marujas - da qual o chapéu é considerado peça fundamental $^{4}$ - não se constituiu como objeto de estudo específico. Com efeito, os elementos que a compõem são frequentemente percebidos como tema incidental, mencionados de forma a atribuir uma função coreográfica aos elementos que a compõem, a exemplo do poema de Maria Lúcia Medeiros (2000):

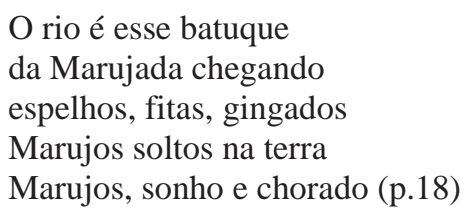

No trecho acima, as palavras "espelhos" e "fitas" se referem a adereços do chapéu das marujas sem que, no entanto, o próprio chapéu seja mencionado. Imagina-se o "gingado" a refletir a luz nos espelhos e a revolver as fitas pelo ar, integrando-as à paisagem dos marujos "soltos na terra" e da marujada que flui como um "rio".

À parte a opção estilística da autora, que se utiliza da linguagem poética para ilustrar a fluidez da memória, o trecho exemplifica não propriamente uma ausência, mas o relativo "desfoque" no tema da indumentária nesta manifestação religiosa: sempre percebida, raramente observada, como se estivesse fixada em um grau de visão periférica que limitasse

\footnotetext{
${ }^{3}$ A data faz referência à fundação da Irmandade do Glorioso São Benedito de Bragança (IGSBB) por negros escravizados. (NONATO DA SILVA, 2006, p. 139)

${ }^{4}$ Este reconhecimento é compartilhado por Carvalho (2010, p.88) e Moraes, Aliverti e Silva (2006, p.69).
} 
maiores reflexões.

Ainda assim, a integração do chapéu à paisagem permite uma outra leitura, bastante elucidativa: o objeto habitando a fronteira entre o humano e o não humano. De fato, o ofício artesanal que o materializa é fruto das técnicas manuais das artesãs que o confeccionam e do sacrifício das aves cujas "plumas" ocupam sua porção superior.

São penas que formam um turbante alvo, erguido sobre um chapéu de palha comum depois que este é recoberto de tecido dourado. Elas são postas, como pétalas, ao redor de um miolo na maioria das vezes vermelho, formando flores atadas à estrutura deste turbante por um arame. Em geral, as penas são retiradas do pato nativo (Cairina moschata), mas há registros da utilização de outras aves, tais como garças (Ardea alba) e guarás (Eudocimus ruber), ou mesmo galinhas (Gallus gallus domesticus) em outras épocas.

Assim como a variedade de plumas, as fitas e espelhos mencionados por Medeiros (2000) coexistem com rosas de tecido, miçangas e paetês multicores, revelando uma espécie de bricolagem que remonta tanto a uma latente religiosidade africana quanto à gradual assimilação de materiais de origens diversas. Durante a pesquisa, pude perceber que tal assimilação é ora aceita, ora rejeitada por ferir a "tradição" que justifica a manutenção de padrões determinados em nome de uma identidade construída historicamente, como demonstrado a seguir.

\section{AVES DE OUTRORA}

Para compreender a utilização de penas de espécies diversas na confecção do chapéu da maruja, é útil elencar descrições - ainda que breves - deste objeto em pesquisas, crônicas e poemas. Postas em ordem cronológica, tais descrições revelam transformações ocultas sob a tradição $o^{5}$ que mantém este saber artesanal, entre as quais a substituição de matérias-primas, a adoção de novas técnicas e a visibilização ou sublimação de determinadas influências.

Ao tratar de edições anteriores da festividade beneditina em Bragança, fontes locais retratam o chapéu da maruja de forma um pouco diferente da que conhecemos hoje. Todos os textos foram publicados a partir da década de 1950. Mais de um século, portanto, depois da fundação da Irmandade de São Benedito e três anos depois da uniformização da marujada de acordo com o calendário festivo, operada por meio do Estatuto da Irmandade do Glorioso São

\footnotetext{
5 Aqui compreendida no sentido etimológico do termo, traditio, do latim "trazer", "entregar" ou "transmitir", sem necessariamente implicar em um engessamento neste processo de transmissão. Tradition: Noun: an inherited pattern of thought or action; a specific practice of long standing. From Latin trāditiō, from the verb trādere. (Advanced English Dictionary, WordNet, Princeton University).
} 
Benedito de Bragança (IGSBB) de $1947^{6}$. A informação que se tem sobre o período anterior é muito restrita.

Dentre estes registros, o primeiro que se tem é a crônica denominada “O Esperado", de Joaquim Lobão da Silveira, publicada em 1952 pela revista Bragança Ilustrada e que compõe a obra "Antologia da Marujada", publicada em 2000 pelo Instituto de Artes do Pará, na qual o autor afirma a existência de chapéus de garça e guará à época:

"E as marujas se enfeitam. Saias encarnadas e azuis. Blusinhas brancas, de rendas. Chapéus de fitas das mais variadas cores, penas de garça e de guará, miçangas e vidrilhos, espelhos e contas. Tudo matizado, tudo alegre." (SILVEIRA, 2000, p.105).

Na mesma edição da revista Bragança Ilustrada, também compilada na "Antologia da Marujada”, Jorge Daniel de Sousa Ramos, em crônica intitulada "O Chamado", escreve:

As pretas e as morenas de saiões vermelhos, casaquinhos brancos, que foram guardados um ano, juntamente com a priprioca e o alecrim dentro da mala, o chapéu de pluma de todas cores, do guará, do pato, aqueles chapéus cheios de espelhinhos, miçangas e outras besteirinhas. (RAMOS, 2000, p.109).

Ramos (2000) vai um pouco além da observação de Silveira (2000), uma vez que fala em "plumas de todas as cores", não necessariamente brancas. Ele menciona novamente chapéus feitos com pena de garça e os feitos com pena de pato, tal como na atualidade. Embora, neste caso, penas de guará não sejam citadas, é possível imaginar que nas "plumas de todas as cores" talvez estivessem incluídas as vermelhas desta ave amazônica.

No ano seguinte, outra edição da mesma revista publicou a crônica "Eu também atendi ao chamado", de autoria de Leandro Ferreira, na qual as marujas são descritas nos termos: "tudo nelas é harmonioso e simétrico, desde o ornato da plumagem dos chapéus ao círculo refletor dos espelhinhos (FERREIRA, 2000, p.113). Aqui cabe, porém, uma crítica no que tange a esta "simetria", que abrange não apenas a plasticidade da plumagem e ao formato circular dos espelhos do chapéu, mas uma suposta igualdade entre brancos e negros na festividade - concepção que eclipsou a hierarquização que incidia sobre indícios de religiosidade africana, silenciando-a e impondo formas de devoção europeizadas - da qual tratarei no decorrer do texto.

\footnotetext{
6 "Uma das primeiras modificações introduzidas na marujada foi o uso de uniformes para os seus participantes. As mulheres, por exemplo, costumavam apresentar-se nos barracões de dança vestindo saias rodadas em chitão estampado nas suas várias tonalidades, camisolas brancas, chapéus enfeitados, porém, sem possuir o caráter de harmonia plástica nas cores azul e vermelho. O uniforme azul e branco, devia ser usado no dia 25 de dezembro, consagrado ao "Dia de Nascimento", numa revivescência do mito do Natal, bem como no da abertura dos festejos (18 de dezembro), e o uniforme vermelho e branco, no dia 26 de dezembro, consagrado a São Benedito de Bragança.” (BRANDÃO DA SILVA, 1997, p. 54).
} 
Ainda na década de 1950, Bordallo da Silva (1959) apresenta as mulheres beneditinas com uma descrição bastante detalhada:

\begin{abstract}
As marujas se apresentam tipicamente vestidas. [...] na cabeça ostentam um chapéu todo emplumado e cheio de fitas multicores. [...] era antigamente feito de feltro, côco ou cartola. Os de fabríco moderno são de carnaúba, palhinha ou mesmo de papelão. Seja qual fôr o material empregado na estrutura básica do chapéu, êle é furado na parte interna e externa. A aba com papel prateado ou estanhado; lateralmente, com papel de côres; e em torno, formando um ou mais cordões em semicírculo, presos nas extremidades, em pontos equidistantes, são colocados voltas ou alças de casquilho dourado, prateado ou colorido. Entre as alças, por cima das voltas, são também colocados espelinhos quadrados ou redondos. Ao alto plumas e penas de aves de diversas cores, formam um largo penacho com mais ou menos cincoenta centímetros de altura. Da aba, na parte posterior do chapéu, descem ao longo da costa da maruja, numerosas fitas multicores. O maior número ou largura das fitas, embora não indicando hierarquia, é reservado às mais antigas. (BORDALLO DA SILVA, 1959, p. 63)
\end{abstract}

O trecho "plumas de aves de diversas cores" diverge das penas unicamente brancas observadas no chapéu das marujas na contemporaneidade, e sugere a utilização de outras aves, tal como apontado por Ramos (2000) e Ferreira (2000), bem como a transformação contínua do saber artesanal quando compara os chapéus de "antigamente" e os de "fabríco moderno".

Na década seguinte, ano de 1963, no romance de nuances autobiográficas "Menina que vem de Itaiara", Lindanor Celina rememora a devoção beneditina que presenciou em Bragança durante a infância ao se referir à capitoa vitalícia da Marujada, tia Joana, da seguinte forma:

Sim, rainha era ela. Seu traje o mais rico, sua saia da roda mais ampla, a anágua mais rendada, o chapéu, o mais cintilante de espelhos e pedrarias, fitas que dele pendiam e lhe chegavam aos pés, as mais abundantes, de mais variado colorido; preso à alvura de sua blusa, o ramo de cravo e alecrim mais perfumado. E o cordão de ouro, as pulseiras e brincos, a faixa a tiracolo? (CELINA, 1963, p. 169)

Embora este trecho da obra de Celina (1963) não mencione penas ou plumas, outros aspectos são dignos de nota: os termos superlativos com que a autora se refere à tia Joana são indícios da função da indumentária como signo de distinção hierárquica, mesmo sendo a personagem, nos demais dias que não os de festividade, uma senhora idosa - "quando a conheci, já netos tinha" (CELINA, 1963, p. 176) - sem posses ou distinção social para além daquele contexto. Esta fluidez de identidade e status é também percebida no poema “Conversa de Marujo", de Aviz de Castro, datado de 1998, que indaga: "Quem são essas mulheres, de pés desnudados, chapéus adornados, com plumas, espelhos, miçangas, colorido de fitas? Quem são essas mulheres de semblantes humildes com vestes tão ricas?" (CASTRO, 
2000, p.20). No poema, porém, as plumas são mencionadas juntos a seus adornos, em oposição ao distanciamento de Celina (1963) quanto ao material.

O historiador Dário Benedito R. Nonato da Silva (2006) menciona somente penas de pato no chapéu. E o faz quando, tal como Celina (1963) aborda, implicações hierárquicas. Ele ressalta a liderança das marujas delineando-as a partir do vestuário: "São as marujas - as mulheres beneditinas - as personagens principais do período, com seus trajes típicos e chapéus turbantes vistosos, brilhosos, enfeitados com fitas multicoloridas e com os penachos brancos de penas de pato." (NONATO DA SILVA, 2006, p.40). O formato de "turbante" é evidenciado e já não se fala em plumas de diversas cores, mas unicamente em "penachos brancos". A variação cromática se restringe às fitas que pendem às costas da maruja, sob a luminosidade do chapéu.

Carvalho (2010) traz uma especificidade ao tema: a autora fala em penas de "pata", sugerindo uma preferência pela matéria-prima retirada das fêmeas ${ }^{7}$ :

Interessante ressaltar o predomínio da participação de mulheres de todas as idades no ritual, com suas saias longas diferenciadas de acordo com o dia e batas brancas, com destaque para o chapéu ornado de penas de pata e longas fitas coloridas. A fita preta é em homenagem aos escravos, reinstituída em 2009. (CARVALHO, 2010, p. 88)

A reinstituição de que trata Carvalho ocorreu por ocasião da declaração da marujada como Patrimônio Cultural Imaterial do Estado do Pará através da Lei no . 7.330, 17 de novembro de 2009, que tem por objetivos "a preservação, conservação e proteção das formas de expressão, objetos, documentos, fantasias ${ }^{8}$, danças e músicas da Marujada" (PARÁ, 2009). A lei reflete uma preocupação antiga quanto a uma suposta "descaracterização", a exemplo do texto de Rosário (2000), que atribui atributos de altivez e alongamento à origem do chapéu da maruja: “(...) faço um apelo às Marujas: erguei os vossos chapéus! Devem eles ser altos, altivos como na origem, expressão de orgulho da gente do Caeté!” (ROSÁRIO, 2000, p.16).

Diante destas questões que tencionam passado e presente, o escopo meramente declaratório do texto legal - embora não faça qualquer menção expressa a componentes da indumentária que devam ser preservados - reacendeu a discussão quanto a combater uma certa modernização do vestuário beneditino. Os organizadores do evento - a Irmandade da Marujada e a Igreja - passaram a recomendar o uso da fita preta em homenagem ao "santo

\footnotetext{
${ }^{7}$ A preferência foi confirmada por algumas artesãs, como tratado no tópico a seguir.

8 Faz-se aqui uma crítica ao termo "fantasias", que não é utilizado pelas marujas. As marujas/artesãs entrevistadas falam ora em "ser maruja" como uma identidade permanente, ora em "sair de maruja" quando se referem ao ato do vestir, evidenciando a indumentária como destinada a um deslocamento no espaço, a procissão.
} 
preto", São Benedito. Estas orientações, porém, se limitam a esforços no sentido de manter ou reabilitar elementos considerados tradicionais.

Como bem observou Hélio Figueiredo da Serra Netto no ensaio fotoetnográfico "O Milagre das Rosas Vermelhas" - referência ao adereço que as marujas levam ao peito - a vestimenta da mulher beneditina "é composta de uma saia vermelha ou azul, acompanhada de uma camisa branca e um chapéu peculiar" (SERRA NETTO, 2015, p. 01). E para conhecer esta peculiaridade do chapéu faz-se necessário recorrer àquelas que o fabricam.

\section{MÃOS E PENAS}

A confecção de chapéus de maruja constitui uma atividade predominantemente feminina, doméstica e noturna, segundo pude observar durante conversas com as artesãs. As entrevistadas são cinco mulheres que aprenderam o ofício com outras mulheres, à exceção de duas delas, irmãs, que contam ter aprendido com o pai. Elas são Elizabeth e Kátia Borges, Maria Alice Costa, Nazareth "Morena" e Aparecida Santos. Todas confeccionam chapéus há mais de dez anos e todas se declaram devotas de São Benedito. De todas elas, apenas Maria Alice Costa não é maruja. Aparecida Santos, Elizabeth e Kátia Borges são promesseiras. Nazareth "Morena” é efetiva ou "do quadro", e assim é identificada na Irmandade.

Elizabeth e Kátia Borges, as irmãs a que me referi no parágrafo anterior, são filhas de um artesão e uma costureira. Trabalham juntas, em um sistema de divisão do trabalho não observado no caso das demais artesãs - Elizabeth monta o chapéu e costura as partes de tecido enquanto Kátia monta habilmente as "rosinhas" - nas quais as penas são dispostas como pétalas - e as coloca em um suporte à espera da fase de montagem. Além dos chapéus, fazem todo tipo de costura e bordados, além de outras peças manuais. Maria Alice Costa trabalha com chapéus de maruja durante todo o ano, aceitando outros tipos de encomendas com menor frequência. Nazareth é aposentada e confecciona chapéus ocasionalmente, entre viagens proporcionadas pela marujada e outras atividades de lazer, que considera um alento para a vida difícil que teve quando mais jovem. Por fim, Aparecida Santos é costureira durante todo o ano e trabalha com chapéus de maruja apenas durante o segundo semestre.

Quase todas as falas se referem à ave que tem sido mais fortemente associada à tradição e provocado o gradual desuso de penas de outras espécies: o pato. Busquei, pelas falas das artesãs, compreender algumas das razões pelas quais se deu esta consolidação e as nuances anímicas que permeiam esta relação.

Ao conversar com Elizabeth Borges, ela declara uma razão prática para a opção: "a 
gente vai atrás de pato. Quando a mamãe comprava pato pro Círio e caía pena, ela juntava. E às vezes tirava pena do pato vivo, do papo, do peito, aquelas mais bonitas, mais redondinhas. A parte do papo a pena já é enrolada, no jeito pra fazer a rosinha do chapéu”. A narrativa remonta aos tempos em que a mãe, Aspásia Borges, costureira e artesã já falecida, tirava proveito do calendário - o Círio de Bragança, em novembro, antecedendo a festividade de São Benedito, realizada no mês seguinte - para preparar o pato no tucupi, prato típico da primeira celebração, removendo e guardando as penas para utilizá-las posteriormente.

Kátia descreve o cuidado com as penas. Segundo ela, todas são lavadas e postas para secar sob um tecido fino, como organza, para que não voem. Se está com pressa para entregar a encomenda, ela liga o ventilador e deixa que as penas sejam revolvidas até que as sequem. “Parece pipoca. As penas que secam vão subindo e eu vou juntando", descreve ela.

Ela então escolhe, tal como fazia sua mãe, penas arredondadas, que imitem a curva que as pétalas apresentam do miolo em direção às suas extremidades. Segundo ela, há partes do corpo do pato, a exemplo do peito, que são propícias para obter este efeito. Quanto ao tipo de pena utilizada, Elizabeth narra uma história sobre as dificuldades de se usar penas de galinha na confecção:

Só presta a de pato. A de galinha é mais barata, mais prática, mas dura no máximo um ano. Quem vai abrir o saco e tirar pra usar no outro ano, ela já tá toda se desfazendo. Uma vez aconteceu isso, a gente faz reforma de chapéu e quando eu fui abrir o saco pra ajeitar o chapéu de uma tia nossa e aconteceu isso, pensei: "Já pensou se eu não abro na frente dela?" Ela ia pensar que eu tinha acabado com o trabalho da outra. E a titia jurava que era pena de pato, mas não era. Também não sei quem fez, ela comprou por aí.

Maria Alice Costa, por sua vez, afirma que, em sua experiência de trinta e cinco anos como artesã, chegou a confeccionar somente dois chapéus em pena de garça - tal como nas crônicas da revista Bragança Ilustrada - por uma encomenda exclusiva, mas não gostou do resultado. "Ah, faz muito tempo! Era gente com dinheiro que queria porque queria ter um. Mas a pena da garça é muito dura, tipo espetada, não fica bonito, não". Ela prefere trabalhar com o pato, porém diferencia o chamado "pato paysandu", cujas penas têm textura irregular, do pato "do nosso", termo pelo qual demonstra sua relação de proximidade com o animal: "o pato paysandu é terrível! A gente olha pra ele e ele tá com uma cara brava, sabe? Uma cara

\footnotetext{
9 O pato paysandu é um híbrido do chamado "pato do mato" ou "pato nativo" (Cairina moschata). É fruto de uma linhagem desenvolvida no estado do Pará nos anos 1990 a partir de cruzamentos entre o chamado pato nativo e linhagens regionais. Existem três linhagens do pato paysandu, identificadas pelas cores branca, cinza e preta. Os espécimes da linhagem branca pesam cerca de $4,1 \mathrm{~kg}$ aos três meses de idade e têm por característica a carne um pouco mais escura e resistente que a do chamado pato nativo (LIMA e LIMA NETO, 2006). O nome deriva da fazenda Paysandu, em Mosqueiro, onde o foi desenvolvida a pesquisa de cruzamentos que resultou nesta subespécie.
} 
fechada. As penas são tudo crespas, não dá pra amarrar o miolo, dá um trabalho... E depois nem fica bom, o chapéu fica todo arrepiado".

A animização do pato é outro aspecto interessante. Na interpretação dela, o pato bravo provoca um produto final assimétrico, enquanto o pato "do nosso", que ela acredita possuir penas mais delicadas, é associado a uma personalidade dócil e a um chapéu mais harmonioso. Este é comprado por ela na feira ou por encomenda junto a parentes em localidades do interior. Tem também uma pequena criação. “Aonde eu sei que tem pato branco, eu vou atrás. Um dia até apareceu um rapaz aqui com nove bicos, porque disseram pra ele que eu comprava".

As penas são guardadas por Alice em um saco azul que, afirma ela, conserva melhor o branco, após terem sido lavadas com um pouco de sabão em pó, água sanitária e amaciante. Uma vez limpas, perfumadas e enxutas, as penas "mais certinhas, mais bonitas" são escolhidas para montar a "flor" e posteriormente "pra terminar vai arrumando, vai puxando, depois faz o aparamento com a tesoura", até que o turbante alcance a altura desejada.

Ao contrário de Alice, Nazareth "Morena" confecciona chapéus esporadicamente:

Não sou aquela que tá fazendo direto. Eu não boto placa, mas o pessoal vem aqui e eu não sei dizer não. Quando eu faço chapéu, eu quase não durmo. A gente dorme pouco. Tem que acordar três horas da madrugada pra fazer flor. De dia é só pra montar o chapéu. Fazer flor não dá, tem muito vento.

Ela prefere montar flores suficientes para dois ou três chapéus antes de começá-los, o que aumenta a quantidade de penas manuseadas de uma vez. Nesta primeira fase, Nazareth utiliza sabão em pó, álcool e um produto para tirar ferrugem diluído em água para lavá-las. Depois, as coloca para secar em um saco de cebolas de feira, "aquele vermelho, todo furadinho" por dois ou três dias, dependendo da intensidade do sol. A mesma exposição ao sol que a artesã recomenda às suas clientes após cada utilização do chapéu. "Usou, colocou no sol, porque o suor corta". Segundo ela, esta prática é suficiente para garantir a durabilidade do chapéu da maruja, desde que o chapéu tenha sido feito com pena de pato.

Nazareth tem suas preferências quanto às penas. E assim como Elizabeth e Kátia, também enumera razões práticas para o uso da pena de pato em detrimento da pena de galinha. "Pena de galinha não presta. Envermelha logo. Se pegar uma chuva, enrola tudinho. E fede". Ela também afirma que a pena da pata é melhor que a do pato, tal como citado por Carvalho (2010). Segundo ela, uma pata é o suficiente para fazer um chapéu, considerando que as penas são retiradas somente do peito, do papo e debaixo das asas. Ela afirma que a pena do macho é mais dura, o que dificulta a retirada do corpo do animal. 
Nazareth não se considera profissional, mas gosta de tentar novas formas de confeccionar o chapéu. Já viu, durante uma viagem, um peru "bem alvinho, não sei se ficava bom pra fazer chapéu. Se eu tivesse dinheiro, tinha trazido pra fazer uma experimentação". E confidencia uma curiosidade: não gosta de comer pato. Ela diz já ter matado tantos patos para fazer seus chapéus que enjoou até o cheiro deles.

E conta uma promessa que fez no passado a São Benedito pela saúde de um dos filhos, mas que foi impedida de pagar por causa do marido, na qual o pato assume ares de protagonista:

Eu morava no interior, lá no Montenegro. São Benedito tava esmolando... Eu escutei
São Benedito. Primeiro ano eu não fez porque o marido era um homem muito
péssimo de ruim. Ele não gostava de... Um pato que eu tirei, esse pato ficou enorme
de grande que era pra mim dar o almoço pro pessoal... No primeiro ano ele não
deixou eu chamar o pessoal, no segundo ano ele não deixou... Quando foi no
segundo ano ele morreu. Antes dele morrer o pato morreu. Tá vendo como é?
Porque o pato era pra fazer almoço pra São Benedito. O pato morreu à toazinha. Eu
fui jogar esse pato fora pra urubu comer... Chorando porque o pato era um homem!
Mas sabe o que é um pato grande? Aí eu digo: "É... Ninguém duvide daquele
pretinho!" Eu ia matar o pato no enterro dele, mas São Benedito não deixou. Quem
comeu o pato foi urubu.

Quando diz que "o pato era um homem", Nazareth equipara a figura do pato à do marido, um a serviço da dívida para com o santo, o outro contrário ao pagamento desta dívida. Pela interpretação que ela faz da ordem dos acontecimentos, São Benedito teria preferido que a carne do pato fosse desperdiçada, perdendo-a para outras aves - os urubus - que perdê-la para o velório daquele que impediu o cumprimento da promessa.

A animização do pato está presente também na fala de Aparecida Santos, que desenvolveu um método próprio para reconhecer os patos que resultariam nos melhores chapéus. Segundo ela, basta observar o comportamento dos animais. Ela descreve o pato “ideal" da seguinte forma:

Quando o pato presta o pato é todo bonitão, é aquele que quer ser todo bonitão. Quer ver, presta atenção quando tu for num sítio assim, quando tiver muita criação. $\mathrm{O}$ paturi parece aqueles meninão, filhinho de papai, todo empinado. Tu percebe. A pena dele é toda arrumadinha. O pato comum já é de qualquer turma, é da bagunça mesmo.

Ela complementa com gestos a analogia aos rapazes da elite, aos quais se refere para definir a postura que serviria ao chapéu, como se o objeto pudesse absorver, ao final do processo, as qualidades atribuídas à ave humanizada, mantendo características como o orgulho e o status. Escolhido o pato, ela recolhe as melhores penas e as coloca dentro de uma bacia de alumínio. Feito isso, cobre a bacia com um tecido fino para que as penas não voem. 
“A pena fica igual uma vitória-régia em cima da água", ela diz. Neste processo, ela utiliza apenas sabão em pó, pois acredita que outros produtos amolecem a pena. O amaciante, de acordo com ela, é o pior dos produtos, pois faz com que elas soltem.

Aparecida já fez chapéus com pena de galinha, mas chegou à mesma conclusão de Nazareth: a pena fica amarelecida facilmente e cheira mal. Para que o chapéu dure, ela diz, são necessárias duas coisas: que a pena seja de pato e que a dona obedeça ao "segredo do chapéu" que "é guardar dentro de uma caixa fechada pra não amarelar as penas".

Nas palavras de Aparecida, toda maruja deve optar por este chapéu e tomar tais cuidados. "Na minha opinião, eu acho que o chapéu tem que ser o tradicional. A maruja de verdade tem chapéu de pena. Aqueles de papel, aquilo ali é só enfeite, no outro ano não presta mais".

\section{A MARUJA "DE VERDADE"}

A fala de Aparecida Santos revela um discurso que pode parecer apenas uma simples forma de valorizar o ofício artesanal, mas reflete atribuições ou estatutos de verdade nas quais o elemento não-humano - o pato - define o humano - a maruja - como sendo "verdadeira", cuidadosa com a forma como se apresenta, ou de "enfeite", como se negligenciasse a própria imagem através de um artefato descartável.

A opinião evidencia uma forte relação entre visualidade e identidade, pois é por meio dos signos corporificados na figura da maruja que é possível identificar o seu papel naquele contexto. Voltando à crônica de Ramos (2000), a marujada "é" a figura feminina das "pretas e as morenas" no aumentativo de seus saiões, no diminutivo dos casaquinhos... E nos chapéus. $\mathrm{O}$ verbo ser evidencia a fusão entre o que se entende como a manifestação ${ }^{10} \mathrm{e}$ as imagens que a tornam perceptível ao espectador.

Tal como na crônica, Miller (2010) advoga a ideia que o ser humano é feito pelos objetos ao mesmo tempo em que os faz, ainda que não o perceba ou que rejeite esta ideia por considerá-la alheia a um conceito de humanidade "imaculada" que, se não se posicionar em oposição à materialidade, é por ela dissolvida:

Trecos são ubíquos e problemáticos. Porém, quaisquer que sejam nossos medos ou preocupações ambientais com o materialismo, não seremos ajudados por uma teoria

\footnotetext{
10 Toma-se aqui a etimologia da palavra "manifestação", oriunda de manus, mão. Manifest: Adjective: clearly revealed to the mind or the senses. Etymology: Middle French manifeste, from Latin manifestus, manufestus ("palpable, evident"), from manus ("hand") + festus, participle of *fendere ("affect, modify, collide with"). (Advanced English Dictionary, WordNet, Princeton University). O trabalho manual das artesãs, portanto, é fundamental nesta relação de identidade.
} 
dos trecos nem por uma atitude que simplesmente nos oponha a eles; como se quanto mais pensássemos nas coisas como se elas fossem alienígenas ou estranhas mais nos mantivéssemos sacrossantos e puros. A ideia de que os trecos de algum modo drenam a nossa humanidade, enquanto nos dissolvemos numa mistura pegajosa de plástico e outras mercadorias, corresponde à tentativa de preservar uma visão simplista e falsa de uma humanidade pura e previamente imaculada. (MILLER, 2010, p.11)

Esta visão "simplista" e "falsa" rechaçada pelo autor pode ser tomada por referência para compreender a marujada. Aqui cabe uma referência ao ditado popular segundo a qual o hábito faz o monge, pois na teia de relações que ali se desenvolvem, a maruja é imediatamente identificada por sua indumentária. As marujas reconhecem-se entre si, bem como são reconhecidas por espectadores da festividade por meio daquilo que reveste seus corpos. Por este motivo, não se questiona que a mulher que se vista como maruja seja, de fato, maruja. Para o espectador, ela se veste como maruja porque o é, e ao mesmo tempo é maruja porque assim se veste, como bem observou Fernandes (2011).

Os marujos e marujas tem sido a representação por natureza da devoção a São Benedito, tanto é que, no período da festividade, o turista diz que vem "ver a marujada em Bragança" e não participar da devoção e procissão ao santo. Pois a marujada - entenda-se não a participação devota de marujos e marujas - é aqui entendida como o vestuário multicolorido de homens e mulheres e as danças que estes praticam no barracão. (FERNANDES, 2011, p. 73)

Da mesma maneira, o cumprimento ou não de certas regras na vestimenta pode indicar se a maruja é "promesseira" ou "efetiva", evidenciando a hierarquia existente naquele contexto.

Ao contrário do que ocorreu com o gradual desuso de penas de outras aves, que implicou na opção majoritária pelas penas do pato, a troca das penas no chapéu por materiais alternativos - tais como algodão, pelúcia ou papel - não goza da mesma aceitação. Constatase, com isso, que a incorporação de materiais ocorre com alguma resistência, evidenciando relações de poder que se desenvolvem na marujada. E isto ocorre porque

\footnotetext{
Moda, indumentária e vestuário constituem sistemas de significados nos quais se constrói e se comunica uma ordem social. Podem operar de diversas maneiras, mas assemelham-se no fato de serem uma das maneiras pelas quais aquela ordem social é vivenciada, compreendida e passada adiante. Podem ser considerados como um dos meios pelos quais os grupos sociais comunicam sua identidade como grupos sociais a outros grupos sociais. São formas pelas quais esses grupos comunicam suas posições em relação àqueles outros grupos sociais. Sem presumir que as diferenças entre esses termos tenham sido ignoradas, é costume afirmar que moda, indumentária e vestuário são apenas formas pelas quais os individuais se comunicam. São também meios pelos quais os grupos sociais se comunicam e geram identificação e/ou rejeição (BARNARD, 2003, p.109)
}

Assim como expôs Barnard (2003), a indumentária comunica posições sociais e gera 
identificações ou rejeições. Tais identificações, evidentemente, estão presentes na marujada. A líder das marujas, chamada "capitoa", possui um bastão que a distingue das demais. As marujas mais idosas que são cadastradas na atual Irmandade da Marujada ${ }^{11}$, conhecidas como "efetivas" ou "do quadro" ostentam trajes e chapéus em conformidade com as "orientações" da instituição, aqui reproduzidas conforme o folheto denominado "São Benedito e os Bragantinos nos 400 Anos de Bragança - Histórico da Irmandade da Marujada de São Benedito de Bragança", elaborado e distribuído por ocasião dos 400 anos da cidade.

À indumentária é dedicada apenas a última página, depois de títulos dedicados à biografia de São Benedito, às esmolações, à cavalhada, às procissões fluvial e terrestre e à dança e instrumentos musicais - nesta ordem - na qual consta não uma mera descrição ou um histórico, como nos títulos anteriores do mesmo folheto, mas orientações expressas sobre o código de vestuário a ser seguido pelas devotas:

\footnotetext{
INDUMENTÁRIA DA MARUJADA

Nos dias 26 de dezembro e $1^{\circ}$ de janeiro

As mulheres usam blusa branca, franzida com pala e rendada, saia vermelha, anágua branca, flor vermelha do lado esquerdo do peito, fita vermelha da direita para a esquerda. Na cabeça ostentam um chapéu dourado com flores brancas feitas de penas de patos e cheio de fitas coloridas, embora não indicam hierarquia era reservado as mais antigas e no pescoço trazem colares coloridos e dourados com medalhas.

(...)

Nos dias 03 de setembro e 18,25 e 31 de dezembro

As mulheres usam blusa branca, franzida com pala e rendada, saia azul, anágua branca, flor azul do lado esquerdo do peito, fita azul da direita para a esquerda. $\mathrm{Na}$ cabeça ostentam um chapéu e no pescoço trazem colares coloridos.

(...)

OBS.: Todos os marujos e marujas efetivos ou promesseiros tem obrigatoriamente que usar o modelo padrão, conforme tradição e pés descalços.
}

As orientações do folheto são expressas quanto ao tipo de pena a ser utilizada: apenas branca, apenas de pato. Há uma minoria entre as marujas, porém, que traz à cabeça chapéus feitos de outros materiais como algodão, pelúcia e papel. Geralmente são "promesseiras" marujas que têm uma dívida de fé com São Benedito, mas que não fazem parte do quadro da Irmandade - e que algumas vezes não têm condições financeiras de adquirir um chapéu de penas, indo à procissão com chapéus alternativos ou improvisados.

Estas marujas acompanham a procissão realizada no dia 26 de dezembro sem maiores incidentes, desde que caminhem entre os demais devotos não uniformizados e não tentem ingressar na "fila das marujas" que saem em cortejo para abrir espaço para o andor de São

\footnotetext{
${ }^{11}$ A IGSBB foi extinta em 1988, após disputas judiciais com a Igreja católica. (BRANDÃo DA SILVA, 1997, p.58).
} 
Benedito. No caso de ingressarem, comumente observa-se o que Barnard (2003) chamou rejeição causada pela indumentária: são muitas as narrativas sobre marujas que destoavam do código de vestuário e que foram advertidas a se retirarem, geralmente por marujas mais antigas, que gozam de autoridade sobre as demais. Marujas que estejam calçadas, ou cujos chapéus não sejam feitos de penas, ou que apresentem quaisquer diferenças de vestuário em relação ao "modelo padrão" a que se refere o folheto estão sujeitas a este tratamento.

Quanto a este fato, o Sr. João Batista Pinheiro, o Careca, presidente da Irmandade da Marujada, afirma que as promesseiras "não podem ser impedidas de pagar sua dívida com o santo", ainda que estejam vestidas "fora da tradição" enquanto acompanham a procissão pelas ruas da cidade. Esta permissão em apresentar-se de forma diversa na via pública, contudo, não se estende aos espaços ocupados pelas marujas "do quadro". Assim como marujas cujo vestuário destoe daquelas pertencentes ao "quadro" são impedidas de ingressar na fila das marujas, elas tampouco podem dançar junto às demais nos momentos de apresentação coreográfica em louvor a São Benedito.

Assim que uma promesseira adentra o salão, ela comunica sua presença por meio do vestuário, sendo percebida pelas marujas efetivas que, sabedoras do código, a observam. Careca narra a história ocorrida há muitos anos na qual "uma moça de outra cidade veio dançar na marujada porque achava bonito" mas vestiu, inadvertidamente, blusa e saia pregueadas. As marujas, ele conta, “começaram a se olhar e comentar baixinho que alguém tinha que fazer alguma coisa, até que elas foram em cima da capitoa pra que ela dissesse pra moça que aquilo não podia”. E, embora a maruja tenha se desculpado e afirmado que não conhecia a regra, a capitoa usou de sua autoridade e pediu à moça que saísse do barracão onde acontecia a dança. O episódio deixa claro que, na marujada, a indumentária delimita os espaços que os sujeitos podem ou não ocupar.

\section{EKODIDÉ: A PLUMA NA RELIGIOSIDADE AFRICANA}

Uma vez abordadas as hierarquias visibilizadas por meio da indumentária na marujada, cabe um contraponto. Trago aqui questões possivelmente sublimadas por trás desta visibilidade: algumas similitudes entre as formas como as aves da marujada e as aves do candomblé são postas à cabeça. E, para tratar de influências africanas no chapéu da maruja, recorro novamente ao folheto nos quais constam normas para o vestuário das marujas. Trago esta referência para esclarecer, no texto, a expressão "tem obrigatoriamente que usar o modelo padrão, conforme tradição" quanto a dois pontos essenciais. 
O primeiro deles é o caráter de uniformização imposto não apenas ao chapéu - mesmo porque, no folheto, a descrição do objeto se resume à cor dourada e às penas e fitas - mas a todo o conjunto de regras que as marujas devem seguir, inclusive quanto às datas reservadas ao azul e ao vermelho. O segundo ponto é revelado pelo trecho "conforme tradição": o código de vestuário deve ser seguido porque a tradição assim o exige. O passado é, então, revestido de uma aura de autoridade, ainda que haja um silenciamento sobre as razões pelas quais tal tradição foi imposta. Além disso, evidencia um esforço por conferir uma identidade visual à manifestação por meio da uniformidade, mesmo que esta nova identidade implique em uma desconstrução de identidades postas à margem. Esta expressão, portanto, revela que as tensões de poder na marujada interferiram e interferem em sua produção imagética, implicando no reconhecimento ou na ocultação de determinados elementos visuais.

Alencar (2013), quando busca os "rastros silenciados" da religiosidade africana na marujada, aponta ao menos três elementos: uma aproximação visual entre a figura da maruja e o orixá Obá ${ }^{12}$, o penacho alongado do chapéu como herança africana dos turbantes femininos e o sacrifício dos patos cujas penas são dispostas acima da estrutura de palha. A autora percebe, no entanto, outras influências:

\begin{abstract}
As marujas nos seus melhores trajes nas cores da carne e do céu, apaziguados pelos tons de branco. São as penas das aves da região bragantina que são usadas para os enfeites do autêntico e tradicional chapéu da maruja. As vestes suntuosas e de renda, os enfeites, as cores em exagero lembram as misturas das etnias entre africanos e europeus: as blusas de renda e os saiões rodados das sinhás e os colares e as guias multicoloridas das mulheres africanas. (ALENCAR, 2013, p.61)
\end{abstract}

Ela percebe ainda que "seria ingenuidade pensar que ostentar as plumas brancas dos patos na cabeça, seja apenas uma ornamentação, um adereço, uma alegoria plástica” (p.84). De fato, é possível perceber similitudes entre o chapéu da maruja e elementos visuais africanos. Um exemplo é uma prática realizada durante a iniciação das filhas-de-santo, chamadas iaôs, nos quais a pena vermelha chamada ekodidé é posta sobre suas cabeças (LÉO NETO, MOURÃO e ALVES, 2011, p.256).

$\mathrm{Na}$ ausência de registros claros sobre o chapéu e as demais peças de indumentária das marujas, Careca se reporta a membros da Irmandade de outros tempos e atribui a eles uma preferência cromática dos escravos quando afirma que "os antigos diziam que os escravos gostavam muito da cor vermelha". A afirmação condiz com a cor da ekodidé do candomblé, bem como com informações levantadas por FREYRE (2003). Em Casa Grande \& Senzala, o

12 Terceira esposa de Xangô, "robusta e trabalhadora”. (VERGER, 1997, p.36) 
autor afirma que:

\begin{abstract}
Aos portugueses parece que a mística do vermelho se teria comunicado através dos mouros e dos negros africanos; [...] E é ainda o encarnado entre os portugueses a cor do amor, do desejo de casamento.' Nos africanos, encontra-se a mística do vermelho associada às principais cerimônias da vida, ao que parece com o mesmo caráter profilático que entre os ameríndios. Nos vários Xangós e seitas africanas que temos visitado no Recife, e nos seus arredores é o vermelho a cor que prevalece, notandose entre os devotos homens de camisa encarnada. Nos turbantes, saias e xales das mulheres de Xangô domina o vermelho vivo. (FREYRE, 2003, p.174)
\end{abstract}

A ekodidé é uma pena retirada da cauda de um pássaro conhecido em português como papagaio africano ou papagaio cinzento (Psittacus erithacus) e que pode sugerir a utilização, no passado, das penas vermelhas do guará na confecção dos chapéus. No ritual de iniciação, a ekodidé tem suma importância, pois

It is precisely in this situation, the creation of a new being, that the importance of these feathers in the initiation rituals of Candomble can be perceived. The symbolic power of the feathers of the ekodide ${ }^{13}$ is based on the creation of a new being, the rebirth of the individual. According to the priests, the feathers also serve to protect the neophyte, who only recently emerged from his/ her reclusion in the camarinha ${ }^{14}$ and would otherwise be susceptible to numerous energetic influences by spirits that could disrupt the following of the true path. A feather is therefore tied by a thin thread of palha-da-costa (Raphia vinifera) to the head of the iaô. (LÉO NETO, MOURÃ̃ e ALVES, 2011, p.256)

Também em relação a este último detalhe, o da palha servindo como suporte à ekodiké, cabe citar as palavras de Careca, segundo o qual nem sempre houve chapéus na marujada. Ele afirma que, nos primeiros anos, homens e mulheres tinham as cabeças adornadas somente por penas presas à cabeça. Com a entrada dos brancos, optou-se pelo chapéu de palha ${ }^{15}$. O fato é que, havendo ou não chapéus desde o início da marujada, os elementos da pena acima da cabeça e da palha junto à testa servindo como uma espécie de suporte estão presentes em ambos os casos.

É sintomático que os pés das marujas estejam descalços, numa alusão à escravidão, enquanto suas cabeças estejam ornamentadas com um chapéu dourado que alonga sua forma. Vale ressaltar, ao levantar questionamentos sobre as origens do chapéu da maruja, que a cabeça tem simbolismo profundo na cultura iorubá. A palavra referente a "ori”, cabeça,

\footnotetext{
13 Termo em iorubá para o papagaio cinzento (Psittacus erythacus).

14 Também chamada "roncó", a camarinha é um cômodo onde o(a) neófito(a) permanece em reclusão antes do ritual de iniciação.

15 Esta versão não condiz com Brandão da Silva (1997, p.54), que de fato afirma ter sido a introdução de uniformes uma modificação trazida pelo mesmo Estatuto de 1947 que admitiu a entrada de brancos na Irmandade Civil. O autor, porém, fala apenas em "chapéus enfeitados" como anteriores a esse "branqueamento", sem dedicar maiores detalhes a este fato.
} 
significa além da cabeça física "divindade pessoal" ou ainda "destino". "Ori, a essência real do ser, guia e ajuda a pessoa desde antes do nascimento, durante toda a vida e após a morte" (Ribeiro, p. 52)

O conceito de ori é tão complexo que a própria palavra que se refere às divindades africanas, "orixá" provém desta mesma raiz. "Ori in Orise means the essence of being, while $\underline{s e^{16}}$ means 'occur', 'originate from' or emerge" (Ademuleya, 2007, p.214). "Orise", "orisé" ou "orixá" seria, portanto, algo como "a origem da essência do ser".

Neste contexto, Ademuleya (2007) percebe a presença desta cosmologia em obras de arte africanas que representam figuras humanas cujas cabeças são deliberadamente aumentadas ou distorcidas. Esta desproporcionalidade anatômica exemplificaria o fato que "ori serves as that 'umbilical cord' connecting man with his God". Ressalte-se que, em muitas culturas, as penas possuem, tal como os pássaros, "heavenly associations" (Gell, 1998, p.112). Por tudo isto, é possível a interpretação que a cabeça, parte do corpo mais próxima do céu, seja alongada para evidenciar esta conexão e recoberta de penas para auxiliar neste "voo" em direção ao sagrado.

Estas considerações são apenas hipóteses sobre a origem das "aves da marujada". Porém, é difícil acessar as origens da utilização de penas no chapéu da maruja, por três razões inafastáveis: uma delas é que a prática de cobrir certas partes do corpo com penas seja comum a várias culturas; outra é a tradição oral na qual são pautadas as culturas africanas, marcadas pela fluidez e escassez de registros; e a última delas é o histórico de disputas pelo controle da festividade ao longo dos anos, sob a qual práticas e relações se reorganizaram, ocultando elementos em detrimento de outros. Ainda assim, as convergências entre as práticas de religiosidade africana e a marujada ressaltam a indumentária como uma "tela de representação" na qual o chapéu exerce função primordial.

O conceito foi proposto por HALL (2003) que, ao discorrer sobre a corpo como único recurso expressivo disponível às culturas africanas subjugadas na diáspora, observou que "essas culturas têm usado o corpo como se ele fosse, e muitas vezes foi, o único capital cultural que tínhamos. Temos trabalhado em nós mesmos como telas de representação" (p. 342). Estas telas expressam repertórios, visibilizam influências e corporificam significados, ainda que submetidas a longos processos de "apropriação, cooptação e rearticulação" (HALL, 2003, p.343) cultural. Neste sentido,

\footnotetext{
${ }^{16}$ Grifos meus.
} 


\begin{abstract}
Não importa o quão deformadas, cooptadas e inautênticas sejam as formas como os negros e as tradições e comunidades negras pareçam ou sejam representadas na cultura popular, nós continuamos a ver nessas figuras e repertórios, aos quais a cultura popular recorre, as experiências que estão por trás delas. Em sua expressividade, sua musicalidade, sua oralidade e na sua rica, profunda e variada atenção à fala; em suas inflexões vernaculares e locais; em sua rica produção de contranarrativas; e, sobretudo, em seu uso metafórico do vocabulário musical, a cultura popular negra tem permitido trazer à tona, até nas modalidades mistas e contraditórias da cultura popular mainstream, elementos de um discurso que é diferente - outras formas de vida, outras tradições de representação. (HALL, 2003, p.342)
\end{abstract}

Por este motivo, as "experiências por trás" destas formas rearticuladas da cultura popular negra de que fala Hall (2003) permanecem, mesmo que ocultas, dispersas ou distorcidas.

\title{
REFLEXO, REFLEXÃO
}

O saber local que materializa o chapéu da maruja perpassa uma relação entre humano e não-humano pela qual são mobilizadas identidades e relações sociais. A opulência do chapéu que paira com suas plumas feito coroa sobre rosas de tecido, brincos, colares, pulseiras, batas, saias e anáguas guarda outras possibilidades de análise.

Há, por parte de alguns atores da marujada, uma veemente repressão quanto a transformações em seus ritos, em uma tentativa de cristalização do rito tal qual este é percebido no presente: parte-se do princípio que a tradição deve se manter como sempre foi, ainda que outras vozes afirmem que nem sempre tenha sido assim. Os atores que advogam em favor desta repressão a justificam pelo princípio supostamente nobre de manter uma certa "pureza" contra hibridizações. No entanto, discursos em nome da "tradição", dos "antigos" e do que era "o certo" servem, paradoxalmente, à negação de elementos que remetem à religiosidade africana. Em favor da origem - compreendida como a marujada reconfigurada pela entrada dos brancos - nega-se a origem - a religiosidade africana que principiou o culto.

O saber artesanal constitui, desta forma, um ângulo privilegiado pelo qual é possível observar indícios desta religiosidade e, ao mesmo tempo, acompanhar transformações silenciosas que facilmente passariam despercebidas até se perderem no tempo como tantas outras modificações. Vale ressaltar que o "perder-se no tempo" aqui não se refere à extinção de determinadas práticas - o que invariavelmente ocorre no âmbito da cultura material - mas à falta de pesquisas que percebam registrem e analisem estas práticas antes que possivelmente desapareçam. Busca-se superar a visão pela qual 
O artesanato, uma das expressões da cultura material, reconhecida como popular, é geralmente visto como depositário de um tempo passado, a residência do antigo em que só se vislumbram aspectos como "pureza", "originalidade" ou qualquer outro estereótipo que o aproxime do tradicional ou arcaico (LIMA, 2005, p.23)

Cada uma das artesãs em questão mais que reproduz a tradição. Elas a produzem a partir de seu repertório simbólico e imagético, sua habilidade técnica, seus valores e senso estético no que tange a materiais, cores, formas, volume e proporções. E dentre esses pontos a serem considerados, a utilização das penas de aves como matéria-prima tem implicações religiosas e práticas.

Este saber se adapta por meio da assimilação de técnicas e da incorporação de materiais tendo em vista a harmonia das formas, a diminuição do tempo e dos custos de confecção, a obediência a certos padrões, a durabilidade e o conforto, razões pelas quais é justificada a utilização de penas de pato. Porém, além desta interação meramente funcional entre o ser humano e o animal, existe a esfera da intepretação religiosa pela qual o ser humano percebe este animal.

Esta interpretação produz reflexos no resultado plástico do produto final - tal como ocorre com a expressão "fechada" do pato paysandu quando associada à textura de suas penas -, revela temas tangenciais como a associação entre celebrações - a exemplo do que ocorre entre o Círio e a marujada, na qual o sacrifício de um único animal serve a dois propósitos - e, no discurso de artesãs e outros sujeitos da marujada, distingue as marujas "verdadeiras" daquelas cujos turbantes são simples "enfeites", de modo a demarcar permissões, proibições e espacialidades. Por este prisma, a ave é bem mais que uma matéria-prima: é um agente que mobiliza identidades, reforça hierarquias e atribui veracidade a um papel social.

\section{REFERÊNCIAS}

ADEMUlEYA, Babasehinde A. The Concept of Ori in the Traditional Yoruba Visual Representation of Human Figures. Nordic Journal of African Studies 16(2): 2007. p. 212220.

ALENCAR, Larissa Fontinelle de. (Des)Silenciando os Rastros da Marujada de São Benedito em Crônicas da Revista Bragança Ilustrada. Nova Revista Amazônica, v. 1 n. 1, p. 48-67, Jan./Jun. 2013.

BRAGANÇA. Inventário da Oferta Turística do Município de Bragança. Secretaria Municipal de Turismo, 2013.

BRANDÃO DA SILVA, Dedival. Os Tambores da Esperança: Um estudo sobre cultura, religião, simbolismo e ritual na festa de São Benedito da cidade de Bragança. Belém: Falangola, 1997. 
CASTRO, Manoel Aviz de. Conversa de Marujo. in.: COUTO, Valentino Dolzane do (org.). Antologia da Marujada. Cadernos IAP, v. 9, Belém, 2000, p.20-25.

CARVALHO, Gisele Maria de Oliveira. A Festa do "Santo Preto": Tradição e percepção da Marujada Bragantina. Brasília, DF. 2010. Dissertação (Mestrado em Desenvolvimento Sustentável) - Centro de Desenvolvimento Sustentável, UnB.

CELINA, Lindanor. Menina que Vem de Itaiara. Rio de Janeiro, Conquista: 1963.

FERNANDES, José Guilherme dos S. Pés que Andam, Pés que Dançam: Memória, identidade e região cultural na esmolação e marujada de São Benedito em Bragança (PA). Belém: EDUEPA, 2011.

FERREIRA, Leandro. Eu Também Atendi ao Chamado. in.: COUTO, Valentino Dolzane do (org.). Antologia da Marujada. Cadernos IAP, v. 9, Belém, 2000, p.111-114.

FREYRE, Gilberto. Casa Grande \& Senzala. 48ª ed. Recife: Global Editora, 2003.

GELL, Alfred. Art and Agency: An anthropological theory. Oxford: Clarendon Press, 1998.

HALL, Stuart. Da Diáspora: Identidades e mediações culturais. Trad.: Adelaine La Guardia Resende et al. Liv Sovik (org.). Belo Horizonte: Editora da UFMG, 2003.

LÉO NETO, Nivaldo Aureliano. MOURÃO, José da Silva. ALVES, Rômulo Romeu Nóbrega. "It All Begins With the Head": Initiation Rituals and the Symbolic Conceptions of Animals in Candomblé. Journal of Ethnobiology, 31(2) Fall/Winter 2011, p. 244-261.

LIMA, R.R.; LIMA NETO, R.R. A Formação da Raça de Pato Paysandu. Belém: Gráfica, 2006. 15 p.

LIMA, Greilson José de. Retalhos e Linhas Tecendo Nossas Imagens: Etnografia do artesanato de bonecas de pano no sítio Riacho Fundo - Esperança-PB. Dissertação de Mestrado apresentada ao Programa de Pós-Graduação em Antropologia da Universidade de Pernambuco. Recife, 2005.

MEDEIROS, Maria Lúcia. Benquerença. in.: COUTO, Valentino Dolzane do (org.). Antologia da Marujada. Cadernos IAP, v. 9, Belém, 2000, p.17-19.

MILLER, Daniel. Trecos, Troços e Coisas: Estudos antropológicos sobre a cultura material. Trad.: Renato Aguiar. Rio de Janeiro: Zahar, 2013.

NONATO DA SILVA, Dário Benedito Rodrigues. Os Donos de São Benedito: Convenções e rebeldias na luta entre o catolicismo tradicional e devocional na cultura de Bragança, século XX. 2006. Dissertação (Mestrado em História Social da Amazônia) - Centro de Filosofia e Ciências Humanas, Universidade Federal do Pará, Belém. 
RAMOS, Jorge Daniel de Sousa. O Chamado. in.: COUTO, Valentino Dolzane do (org.). Antologia da Marujada. Cadernos IAP, v. 9, Belém, 2000, p.108-110.

RIBEIRO, Berta G et al. O Artesão Tradicional e Seu Papel na Sociedade Contemporânea. Brasília: FUNARTE/Instituto Nacional do Folclore, 1983.

RIBEIRO, Ronilda Iyakemi. Alma Africana no Brasil: Os iorubás. São Paulo: Oduduwa, 1996.

ROSÁRIO, Ubiratan. Saga do Caeté: Folclore, história, etnografia e jornalismo na cultura amazônica da marujada. Zona bragantina, Pará. Belém: Edições CEJUP, 2000.

SERRA NETTO, Hélio Figueiredo da. O Milagre das Rosas Vermelhas: Corporalidade, fotografia e sacralidade na Marujada de Bragança-Pará. Porto Alegre: Revista Iluminuras, v. 16, n. 37, 2015.

SILVA, Dedival Brandão da. Os Tambores da Esperança: Um estudo sobre cultura, religião, simbolismo e ritual na festa de São Benedito da cidade de Bragança. Belém: Falangola, 1997.

SILVEIRA, Lobão da. O Esperado (Crônica publicada na revista Bragança Ilustrada em 1952). in.: COUTO, Valentino Dolzane do (org.). Antologia da Marujada. Cadernos IAP, v. 9 , Belém, 2000, p.105-107.

SOUZA, Diego Tarcísio Matos de Sousa; DUARTE, Maria Marize; MIRANDA, Rosinda da Silva. Religiosidade, Experiências e Saberes: Evidenciados na festa da marujada do glorioso São Benedito em Bragança Pará. (Anais do XIV Simpósio Nacional da ABHR Juiz de Fora - MG, p.1087 a 1095, 15 a 17 de abril de 2015)

SOUZA, Marina de Mello. Catolicismo Negro no Brasil: Santos e minkisi, uma reflexão sobre miscigenação cultural. Afro-Ásia, no 28, 2000, p.125-146.

VERGER, Pierre. Lendas Africanas dos Orixás. Trad. Maria Aparecida da Nóbrega. $4^{\mathrm{a}}$ ed. Salvador: Corrupio: 1997, 96 p. 